\title{
Chemical segregation of complex organic O-bearing species in Orion $\mathrm{KL}^{\star}$
}

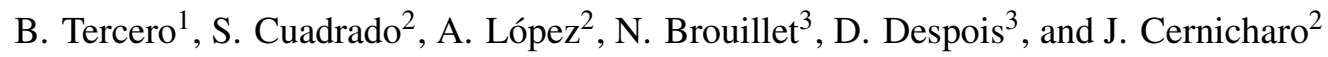 \\ 1 Observatorio Astronómico Nacional (OAN-IGN), Calle Alfonso XII, 3, 28014 Madrid, Spain \\ e-mail: b.tercero@oan.es \\ 2 Instituto de Física Fundamental (IFF-CSIC), Calle Serrano 123, 28006 Madrid, Spain \\ e-mail: s.cuadrado@csic.es \\ 3 Laboratoire d'astrophysique de Bordeaux, Univ. Bordeaux, CNRS, B18N, allée Geoffroy Saint-Hilaire, 33615 Pessac, France \\ e-mail: jose.cernicharo@csic.es
}

Received 12 October 2018 / Accepted 15 November 2018

\begin{abstract}
We investigate the chemical segregation of complex O-bearing species (including the largest and most complex ones detected to date in space) towards Orion KL, the closest high-mass star-forming region. The molecular line images obtained using the ALMA science verification data reveal a clear segregation of chemically related species depending on their different functional groups. We map the emission of ${ }^{13} \mathrm{CH}_{3} \mathrm{OH}, \mathrm{HCOOCH}_{3}, \mathrm{CH}_{3} \mathrm{OCH}_{3}, \mathrm{CH}_{2} \mathrm{OCH}_{2}, \mathrm{CH}_{3} \mathrm{COOCH}_{3}, \mathrm{HCOOCH}_{2} \mathrm{CH}_{3}, \mathrm{CH}_{3} \mathrm{CH}_{2} \mathrm{OCH}, \mathrm{HCOOH}$, $\mathrm{OHCH}_{2} \mathrm{CH}_{2} \mathrm{OH}, \mathrm{CH}_{3} \mathrm{COOH}, \mathrm{CH}_{3} \mathrm{CH}_{2} \mathrm{OH}, \mathrm{CH}_{3} \mathrm{OCH}_{2} \mathrm{OH}, \mathrm{OHCH}_{2} \mathrm{CHO}$, and $\mathrm{CH}_{3} \mathrm{COCH}_{3}$ with $\sim 1.5^{\prime \prime}$ angular resolution and provide molecular abundances of these species toward different gas components of this region. We disentangle the emission of these species in the different Orion components by carefully selecting lines free of blending and opacity effects. Possible effects in the molecular spatial distribution due to residual blendings and different excitation conditions are also addressed. We find that while species containing the $\mathrm{C}-\mathrm{O}-\mathrm{C}$ group, i.e. an ether group, exhibit their peak emission and higher abundance towards the compact ridge, the hot core south is the component where species containing a hydroxyl group $(-\mathrm{OH})$ bound to a carbon atom $(\mathrm{C}-\mathrm{O}-\mathrm{H})$ present their emission peak and higher abundance. This finding allows us to propose methoxy $\left(\mathrm{CH}_{3} \mathrm{O}-\right)$ and hydroxymethyl $\left(-\mathrm{CH}_{2} \mathrm{OH}\right)$ radicals as the major drivers of the chemistry in the compact ridge and the hot core south, respectively, as well as different evolutionary stages and prevailing physical processes in the different Orion components.
\end{abstract}

Key words. astrochemistry - line: identification - ISM: abundances - ISM: clouds - ISM: molecules

\section{Introduction}

Orion BN/KL (Becklin-Neugebauer/Kleinmann-Low) is the closest high-mass star-forming region ( 400 pc; Grossschedl et al. 2018; Kounkel et al. 2017; Menten et al. 2007) exhibiting several processes related to young stellar objects and high-mass star formation (see, e.g. Genzel \& Stutzki 1989). This region is located at the core of the Orion Molecular Cloud 1 (OMC 1), which lies behind the Orion Nebula cluster (O'Dell 2001). The core of Orion KL contains at least three self-luminous objects (protostars), the compact $\mathrm{H}$ II regions $I, n$, and $B N$; these sources are within a region of $\sim 10^{\prime \prime}(\sim 0.02 \mathrm{pc})$. Their proper motions reveal that they are moving away from a common region (Gómez et al. 2005). Different scenarios, as well as the formation of high-mass stars, have been proposed to explain the complexity of this source. An explosion of a multi-star system (sources $I, n, x$, and $B N$ ) that took place $\sim 500$ years ago (Gómez et al. 2005; Bally et al. 2017; Luhman et al. 2017;

\footnotetext{
* This paper makes use of the following ALMA data: ADS/JAO.ALMA\#2011.0.00009.SV. ALMA is a partnership of ESO (representing its member states), NSF (USA), and NINS (Japan), together with NRC (Canada), NSC and ASIAA (Taiwan), and KASI (Republic of Korea), in cooperation with the Republic of Chile. The Joint ALMA Observatory is operated by ESO, AUI/NRAO, and NAOJ.
}

Rodríguez et al. 2017) has been proposed as the main factor responsible for most of Orion KL gas components (Zapata et al. 2011).

The different gas components show distinct physical and chemical properties. Classically, these components have been identified with single-dish telescopes by a characteristic systemic velocity (Blake et al. 1987; Schilke et al. 2001; Tercero et al. 2010): (i) hot core, a hot ( $T \simeq 200-300 \mathrm{~K})$, dense clump rich in complex organic saturated $\mathrm{N}$-bearing species such as $\mathrm{CH}_{3} \mathrm{CH}_{2} \mathrm{CN}$, characterised by $\Delta v \simeq 5-15 \mathrm{~km} \mathrm{~s}^{-1}$ and $v_{\mathrm{LSR}} \simeq 5-7 \mathrm{~km} \mathrm{~s}^{-1}$; (ii) extended ridge, the host, quiescent, and relatively cold $(T \simeq 60 \mathrm{~K})$ ambient cloud rich in simple species such as $\mathrm{CS}$ or $\mathrm{HCN}$, emitting lines with $\Delta v \simeq 3-4 \mathrm{~km} \mathrm{~s}^{-1}$ and $v_{\mathrm{LSR}} \simeq 8-9 \mathrm{~km} \mathrm{~s}^{-1}$; (iii) compact ridge, a warm $(T \simeq 150 \mathrm{~K})$, compact clump rich in organic saturated O-rich species such as $\mathrm{HCOOCH}_{3}$ or $\mathrm{CH}_{3} \mathrm{OCH}_{3}$, whose spectral features are characterised by $\Delta v \simeq 2-3 \mathrm{~km} \mathrm{~s}^{-1}$ and $v_{\mathrm{LSR}} \simeq 7-8 \mathrm{~km} \mathrm{~s}^{-1}$; and (iv) plateau, molecular outflows presenting typical shock chemistry with molecules such as SO or $\mathrm{SiO}$ (Tercero et al. 2011; Goicoechea et al. 2015); here the low-velocity flow is characterised by lines with $\Delta v \simeq 20 \mathrm{~km} \mathrm{~s}^{-1}$ and $v_{\mathrm{LSR}} \simeq 5-6 \mathrm{~km} \mathrm{~s}^{-1}$ (Bell et al. 2014), whereas the highvelocity flow presents lines with $\Delta v$ as wide as $150 \mathrm{~km} \mathrm{~s}^{-1}$ and $v_{\mathrm{LSR}} \simeq 10 \mathrm{~km} \mathrm{~s}^{-1}$. 
In the recent years, data from the last generation of telescopes have added further complexity to this region. Neill et al. (2013) and Crockett et al. (2014) noted that a component between hot core and compact ridge, called the hot core south $\left(\Delta v \simeq 5-10 \mathrm{~km} \mathrm{~s}^{-1}\right.$ and $\left.v_{\mathrm{LSR}} \simeq 6.5-8 \mathrm{~km} \mathrm{~s}^{-1}\right)$ was required to correctly model the Herschel-HIFI emission of several molecules. In these works, this component was also revealed by mapping the emission of $\mathrm{HDO},{ }^{13} \mathrm{CH}_{3} \mathrm{OH},{ }^{13} \mathrm{CH}_{3} \mathrm{CN}$, and $\mathrm{HCOOCH}_{3}$ using the ALMA Science Verification (SV) data. Moreover, Peng et al. (2012) previously noted that the strongest $\mathrm{CH}_{2} \mathrm{DOH}$ and $\mathrm{CH}_{3} \mathrm{OH}$ emissions come from the hot core south-west region with a velocity that is typical of the compact ridge.

This new component is especially important regarding the spatial distribution of the complex organic O-bearing molecules. A series of recent works based on interferometric data have demonstrated a clear spatial differentiation between the most complex O-bearing species detected in Orion KL. On the one hand, the following species (among others) emit from the compact ridge component: $\mathrm{HCOOCH}_{3}$ (Favre et al. 2011a; Widicus Weaver \& Friedel 2012; Crockett et al. 2014; Tercero et al. 2015; Cernicharo et al. 2016), $\mathrm{CH}_{3} \mathrm{OCH}_{3}$ (Favre et al. 2011b; Widicus Weaver \& Friedel 2012; Brouillet et al. 2013; Feng et al. 2015; Tercero et al. 2015; Cernicharo et al. 2016), $\mathrm{CH}_{3} \mathrm{OH}$ (Friedel \& Widicus Weaver 2012; Peng et al. 2012; Neill et al. 2013; Feng et al. 2015; Tercero et al. 2015; Cernicharo et al. 2016), $\mathrm{CH}_{3} \mathrm{CH}_{2} \mathrm{OCH}_{3}$ (Tercero et al. 2015), $\mathrm{HCOOCH}_{2} \mathrm{CH}_{3}$ (Tercero et al. 2015), and $\mathrm{CH}_{2} \mathrm{OCH}_{2}$ (Cernicharo et al. 2016). On the other hand, complex organic O-rich species, whose major emission is associated with the hot core south, emit far away the compact ridge: $\mathrm{CH}_{3} \mathrm{COCH}_{3}$ (Widicus Weaver \& Friedel 2012; Peng et al. 2013; Feng et al. 2015; Cernicharo et al. 2016), $\mathrm{OHCH}_{2} \mathrm{CH}_{2} \mathrm{OH}$ (Brouillet et al. 2015; Cernicharo et al. 2016; Favre et al. 2017), $\mathrm{CH}_{3} \mathrm{COOH}$ (Cernicharo et al. 2016; Favre et al. 2017), $\mathrm{CH}_{3} \mathrm{CH}_{2} \mathrm{OH}$ (Feng et al. 2015; Tercero et al. 2015); Cernicharo et al. 2016), and $\mathrm{OHCH}_{2} \mathrm{CHO}$ (Cernicharo et al. 2016). Favre et al. (2017) proposed that the rich molecular composition of the Orion core, which exhibits the emission peak of $\mathrm{OHCH}_{2} \mathrm{CH}_{2} \mathrm{OH}$ and $\mathrm{CH}_{3} \mathrm{COOH}$, may reflect gas-phase chemistry in an induced shock or post-shock stage due to the impact of a bullet of matter ejected during the explosive event of Orion KL (Wright \& Plambeck 2017).

Chemical segregation of complex organic molecules (COMs, Herbst \& van Dishoeck 2009) in star-forming regions has been investigated concerning the spatial differentiation between the O- and N-bearing species (Peng et al. 2013; Öberg et al. 2013; Fayolle et al. 2015; Jiménez-Serra et al. 2016; Allen et al. 2017; Bergner et al. 2017; Suzuki et al. 2018). However, information about the spatial distribution of chemically related COMs is lacking, mostly due to the low abundances of the most complex species which prevent the detection of these species in the majority of star-forming regions. The identification of several O-bearing COMs in Orion KL allows us to investigate the spatial distribution of similar species (in terms of complexity and variety of atoms) but harbouring different chemical functional groups to test the COM formation and evolution.

In this Letter we investigate the spatial distribution of O-bearing COMs and some related species detected in this source based on the ALMA SV data, including, for the first time, the largest and most complex Obearing COMs detected to date in space (Sect. 3): ${ }^{13} \mathrm{CH}_{3} \mathrm{OH}$ (methanol), $\mathrm{HCOOCH}_{3}$ (methyl formate), $\mathrm{CH}_{3} \mathrm{OCH}_{3}$ (dimethyl ether), $\mathrm{CH}_{2} \mathrm{OCH}_{2}$ (oxirane), $\mathrm{CH}_{3} \mathrm{COOCH}_{3}$ (methyl acetate), $\mathrm{HCOOCH}_{2} \mathrm{CH}_{3}$ (ethyl formate), $\mathrm{CH}_{3} \mathrm{CH}_{2} \mathrm{OCH}_{3}$ (ethyl methyl ether), $\mathrm{HCOOH}$ (formic acid), $\mathrm{OHCH}_{2} \mathrm{CH}_{2} \mathrm{OH}$ (ethylene glycol), $\mathrm{CH}_{3} \mathrm{COOH}$ (acetic acid), $\mathrm{CH}_{3} \mathrm{CH}_{2} \mathrm{OH}$ (ethanol), $\mathrm{CH}_{3} \mathrm{OCH}_{2} \mathrm{OH}$ (methoxymethanol), $\mathrm{OHCH}_{2} \mathrm{CHO}$ (glycolaldehyde), and $\mathrm{CH}_{3} \mathrm{COCH}_{3}$ (acetone). In addition, molecular abundances have been derived for all these species in different regions of Orion. Finally, we discuss the observed chemical differentiation in Sect. 4.

\section{Observations}

The ALMA Science Verification (SV) data ${ }^{1}$ were taken in January 2012 towards the IRc 2 region in Orion. The observations were carried out with 16 antennas of $12 \mathrm{~m}$ in the frequency range from $213.715 \mathrm{GHz}$ to $246.627 \mathrm{GHz}$ (Band 6). The primary beam was $\sim 27^{\prime \prime}$. Spectral resolution was $0.488 \mathrm{MHz}\left(\sim 0.64 \mathrm{~km} \mathrm{~s}^{-1}\right.$ in the observed frequency range). The observations were centred on $\alpha_{\mathrm{J} 2000}=05^{\mathrm{h}} 35^{\mathrm{m}} 14.35^{\mathrm{s}}, \delta_{\mathrm{J} 2000}=-05^{\circ} 22^{\prime} 35.00^{\prime \prime}$. The CASA software $^{2}$ was used for initial processing, and then the visibilities were exported to the GILDAS package ${ }^{3}$ for further analysis. The line maps were cleaned using the HOGBOM algorithm (Högbom 1974). The synthesised beam ranged from $2.00^{\prime \prime} \times 1.48^{\prime \prime}$ with a position angle (PA) of $176^{\circ}$ at $214.0 \mathrm{GHz}$ to $1.75^{\prime \prime} \times 1.29^{\prime \prime}$ with a PA of $164^{\circ}$ at $246.4 \mathrm{GHz}$. The brightness temperature to flux density conversion factor is $9 \mathrm{~K}$ for $1 \mathrm{Jy}$ per beam. The continuum emission was subtracted in the maps by carefully selecting line-free channels.

\section{Results}

Several O-bearing COMs have been identified towards different Orion components. In this work we study the most complex ones together with some related species: alcohols, ${ }^{13} \mathrm{CH}_{3} \mathrm{OH}, \mathrm{CH}_{3} \mathrm{CH}_{2} \mathrm{OH}, \mathrm{OHCH}_{2} \mathrm{CH}_{2} \mathrm{OH}$, and $\mathrm{CH}_{3} \mathrm{OCH}_{2} \mathrm{OH}$; ethers, $\mathrm{CH}_{3} \mathrm{OCH}_{3}, \mathrm{CH}_{2} \mathrm{OCH}_{2}$, and $\mathrm{CH}_{3} \mathrm{CH}_{2} \mathrm{OCH}_{3}$; ketones, $\mathrm{CH}_{3} \mathrm{COCH}_{3}$; aldehydes, $\mathrm{OHCH}_{2} \mathrm{CHO}$ (only tentatively detected); esters, $\mathrm{HCOOCH}_{3}, \mathrm{HCOOCH}_{2} \mathrm{CH}_{3}$, and $\mathrm{CH}_{3} \mathrm{COOCH}_{3}$; and carboxylic acids, $\mathrm{HCOOH}$ and $\mathrm{CH}_{3} \mathrm{COOH}$. We have detected methoxymethanol for the first time in Orion (for laboratory spectroscopy of methoxymethanol see Motiyenko et al. 2018) and the second in interstellar medium (McGuire et al. 2017).

Owing to the high spatial resolution of the ALMA SV data that distinguishes between the contributions from the different cores of Orion, we constrained the spatial distributions of these species and their abundances. To perform the ALMA maps, we selected two transitions of each of these species that arise free of blending with other species in the Orion KL cores (see Table A.1 and Fig. C.1). When possible, the two selected transitions have large differences in the energy of the upper level state. Then, for each species, the spatial distribution of the integrated line emission of the two selected lines was overlapped by depicting it in different visual scales (colour and contours; see Fig. 1). Doing so, we addressed possible effects in the spatial distribution related to different excitation conditions and potential blendings of the lines with other species in the different components.

Moreover, to limit opacity effects in the emission distribution of the most abundant species, we mapped $a$-type transitions

\footnotetext{
1 http://almascience. eso.org/almadata/sciver/ OrionKLBand6/

2 http://casa.nrao.edu

http://www . iram. fr/IRAMFR/GILDAS
} 
B. Tercero et al.: Chemical segregation of complex organic O-bearing species in Orion KL
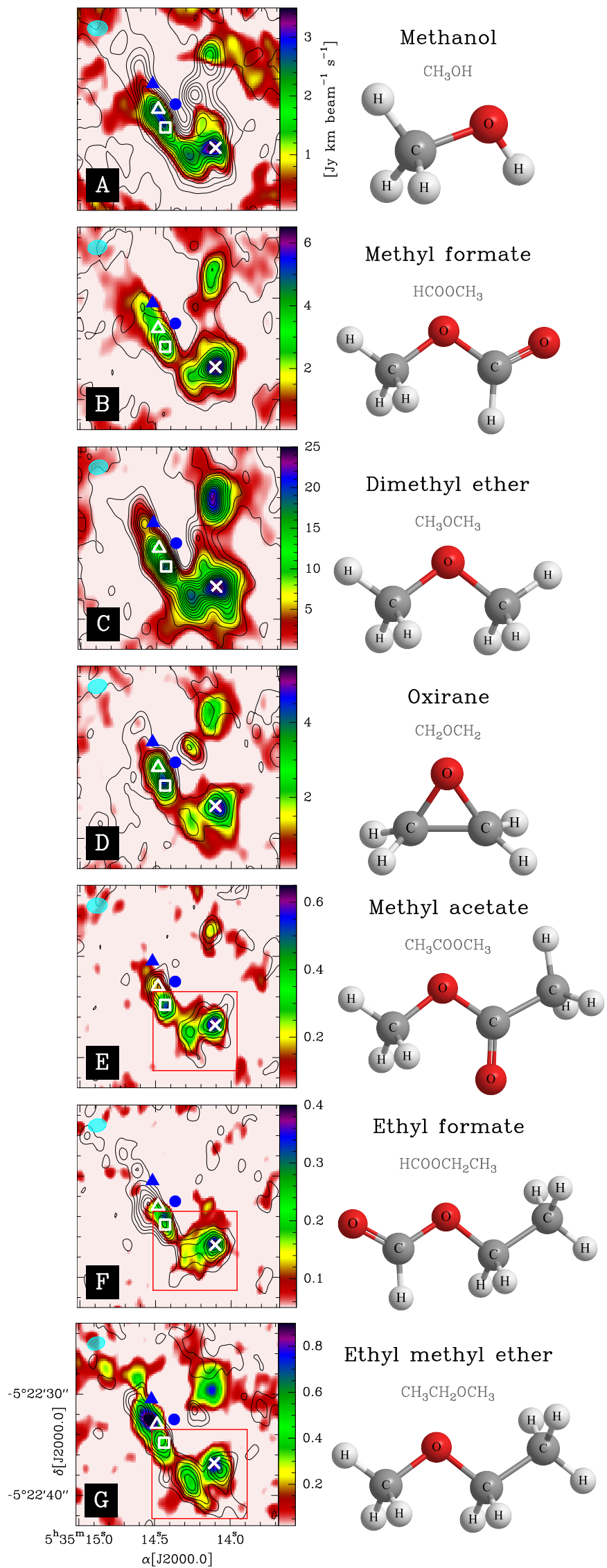

Ethyl formate

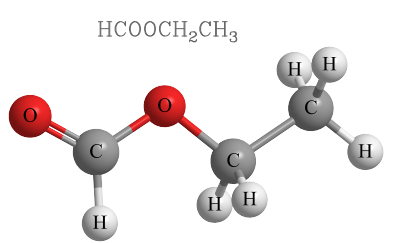

Ethyl methyl ether

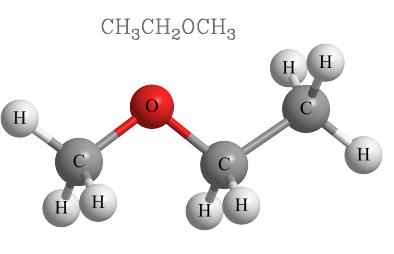

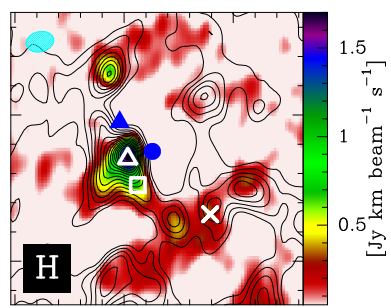
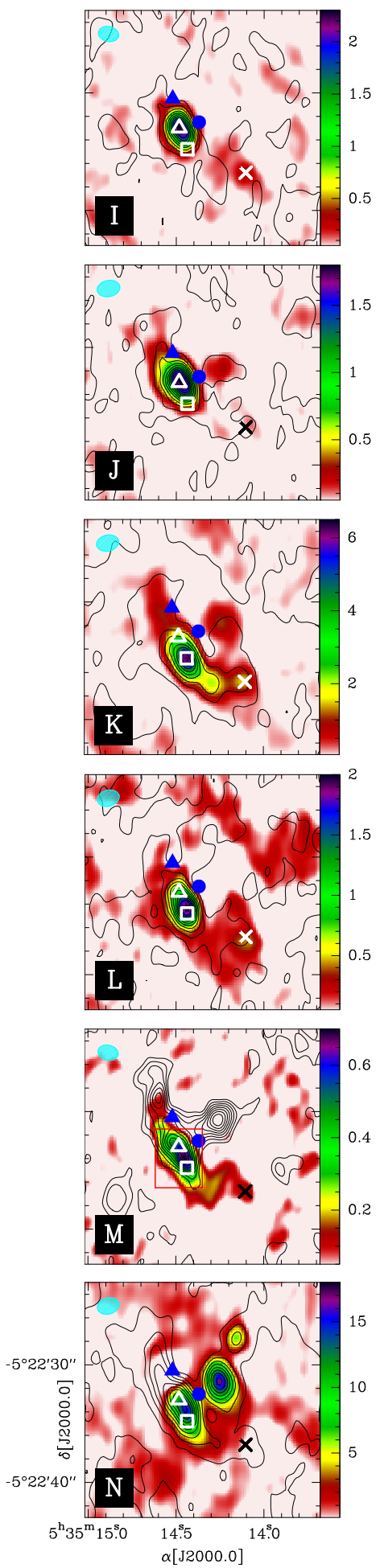

Glycolaldehyde

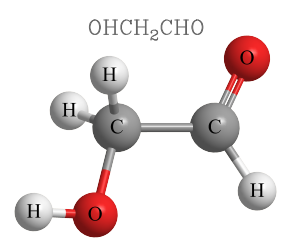

Acetone

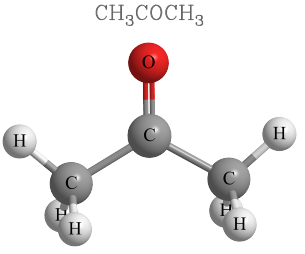

Fig. 1. Spatial distribution of O-bearing species in Orion KL (see text, Sect. 3). The different positions discussed in the text are indicated by symbols (blue triangle: source $I$; blue circle: source $n$; cross: MF peak; unfilled triangle: EG peak; unfilled square: ET peak). The cyan ellipse in the top left corner of each map represents the ALMA synthetic beam. Red rectangles confine the assumed spatial distribution for E, F, G, and M species. The values of the levels are shown in Table A.1. 
of ${ }^{13} \mathrm{CH}_{3} \mathrm{OH}$ and $b$-type transitions of $\mathrm{HCOOCH}_{3}$ (those associated with the lowest dipole moment of each species). Despite the lack of short spacing data required for completion of the possible extended emission of some of these species (see e.g. ${ }^{13} \mathrm{CH}_{3} \mathrm{OH}$ or $\mathrm{HCOOH}$ ), we obtain an overview of the main cores that host the studied species.

We note the coincidence in the emission peaks between colour and contour scales for most of the species (see Fig. 1). Only for the less abundant species are there some regions which exhibit emission only in one of the depicted lines due to light blendings with other molecular species in a particular region of the cloud (see Table A.1 and Fig. C.1). In those cases $\left(\mathrm{CH}_{3} \mathrm{COOCH}_{3}, \mathrm{HCOOCH}_{2} \mathrm{CH}_{3}, \mathrm{CH}_{3} \mathrm{CH}_{2} \mathrm{OCH}_{3}\right.$, and $\mathrm{OHCH}_{2} \mathrm{CHO}$ ) we assumed only the overlapping areas (colour + contours) as the emitting regions for these species (emission confined inside red rectangles in Fig. 1).

Figure 1 shows the ALMA maps together with the molecular structure of the corresponding species for all complex Obearing molecules mentioned above. At first glance there is a clear differentiation in the spatial distribution of the species situated at the two different sides of Fig. 1: the molecules on the left (panels A-G) present the bulk of the emission at the position of the compact ridge (crosses), the emission of the species on the right (panels $\mathrm{H}-\mathrm{N}$ ) is characterised by a lack of a significant contribution towards this component. Moreover, the species on the right do not present a common emission peak towards their main emitting region (the hot core south). We distinguished two locations separated by about $\sim 1.6^{\prime \prime}$ for the main emission peaks in the hot core south: the maximum of formic acid (H), ethylene glycol (I), and acetic acid (J), in agreement with the position found in other works (Brouillet et al. 2015; Cernicharo et al. 2016; Favre et al. 2017; Pagani et al. 2017) for these species (unfilled triangles) and the maximum of ethanol (K) and methoxymethanol (L) (unfilled squares). In addition, we note that the species which present compact ridge emission (A-G) also exhibit emission in the hot core south showing a maximum in a position near the unfilled square (emission peak of ethanol and methoxymethanol). It is worth noting that a clump at the north-west appears in the emission of species $\mathrm{A}, \mathrm{B}, \mathrm{C}, \mathrm{D}$, and $\mathrm{E}$, thus presenting the chemical fingerprints found for the compact ridge (see e.g. Favre et al. 2011a, Wu et al. 2014, and Hirota et al. 2015 for further discussion of this component). However, we cannot confirm emission from the less abundant species of this group ( $F$ and $G$ ) towards this component.

Owing to the observed spatial distributions of these species, we distinguish three emission peaks for further discussions (see Fig. 1): MF (methyl formate peak, cross symbol), EG (ethylene glycol peak, unfilled triangle), and ET (ethanol peak, unfilled square). Coordinates for these positions are shown in Table B.1. Interestingly, these emission peaks coincide with three continuum sources found by Hirota et al. (2015) at $245 \mathrm{GHz}$ and $339 \mathrm{GHz}$ using subarcsecond resolution observations performed with the ALMA interferometer: HKKH 11 for the MF peak, HKKH 9 for the ET peak, whereas HKKH 8 is close to EG peak (see Fig. 4 and Table 3 of Hirota et al. 2015). In addition, Wright \& Plambeck (2017) show that these continuum sources lie along the boundaries of the $\mathrm{SiO}$ outflow emission, being $\mathrm{HKKH} 8$ (EG peak) the more embedded source in the $\mathrm{SiO} J=2 \rightarrow 1$ emission (see Fig. 1 of Wright \& Plambeck 2017). Moreover, Brouillet et al. (2015) noted that one short CO jet identified by Zapata et al. (2009) overlaps the EG peak, which suggests that this component may also be located in the path of the high-velocity outflow.

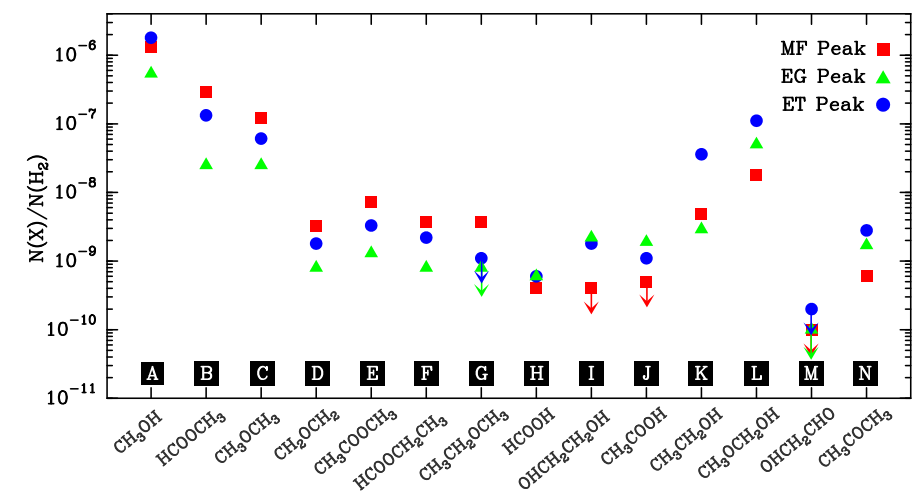

Fig. 2. Abundances of complex O-bearing species in Orion KL.

We used the MADEX ${ }^{4}$ radiative transfer code (Cernicharo et al. 2012) to derive physical parameters and column densities for the studied species towards the MF, EG, and ET peaks (see Appendix B). Figure C.1 shows the lines mapped in Fig. 1 (colour and contours) in the three selected positions (MF, EG, and ET peaks) together with the adopted integrated area for imaging the spatial distribution of these lines and the synthetic spectrum provided by MADEX. In addition, to ensure the first detection of methoxymethanol in Orion, Fig. C.2 shows selected lines of $\mathrm{CH}_{3} \mathrm{OCH}_{2} \mathrm{OH}$ in the ET peak together with the model derived using MADEX according to the physical parameters given in Table B.1.

Molecular abundances for each species in the different positions were calculated using the derived column densities shown in Table B.1. We adopted the $N\left(\mathrm{H}_{2}\right)$ values of $8.2 \times 10^{23}$, $2.4 \times 10^{24}$, and $1.8 \times 10^{24} \mathrm{~cm}^{-2}$ derived by Hirota et al. (2015) in HKKH 11 (MF), HKKH 8 (EG), and HKKH 9 (ET), respectively, using a dust temperature of $100 \mathrm{~K}$ and a modified blackbody fitting of the spectral energy distribution (SED). Figure 2 shows the molecular abundances obtained for the studied species in the different positions. Interestingly, the derived values reproduce the same tendency observed in the maps. While species from A to G exhibit the lowest abundance towards the EG peak, the MF peak is the position where species from $\mathrm{H}$ to $\mathrm{N}$ present lower abundances.

\section{Discussion}

The clear spatial segregation of the studied O-bearing species allows us to infer some common evident molecular features for these molecules depending on whether they present significant emission in the compact ridge component or not. All molecules from $B$ to $G$ harbour an oxygen bound to two carbons by two single bonds ( $\mathrm{C}-\mathrm{O}-\mathrm{C}$; an ether group), whereas all species from $\mathrm{H}$ to $\mathrm{M}$ show a hydroxyl group $(-\mathrm{OH})$ bound to a carbon atom $(\mathrm{C}-\mathrm{O}-\mathrm{H})$. This points to a principal common precursor for the formation (via dust and/or gas-phase reactions) of these species. According to this molecular structure, we propose methoxy $\left(\mathrm{CH}_{3} \mathrm{O}-\right)$ and hydroxymethyl $\left(-\mathrm{CH}_{2} \mathrm{OH}\right)$ radicals as the major drivers of the chemistry in the compact ridge and the hot core south, respectively. Nevertheless, studies on laboratory experiments on ices and surface and/or gas-phase chemical models could point in alternative directions. Paying attention to these studies, the chemical fingerprints found in this work, the positions of MF, EG, and ET peaks along Orion $\mathrm{KL}$, and assuming similar initial conditions for the parent cloud, we could propose several scenarios for the chemical segregation found in this paper.

\footnotetext{
4 https://nanocosmos.iff.csic.es/?page_id=1619
} 


\subsection{Surface and gas-phase chemistry}

Our results show that $\mathrm{C}-\mathrm{O}-\mathrm{C}$-bearing species are present both at the hot core south and the compact ridge, but peak at the latter. Due to the recent explosive event $(500-1000 \mathrm{yr})$ in Orion, we could expect a young stage for the chemistry of this region. The simplest model to explain the rather strong correlation of these species is radical-radical reactions on grain surfaces (see Garrod et al. 2008). Then the relative abundances of the $\mathrm{C}-\mathrm{O}-\mathrm{C}$-bearing species may be fixed before this event and the absolute abundances could be enhanced after the explosion. Moreover, the hot core south could be more exposed to the effects of this event (i.e. higher temperature, particles, or shocks) giving rise to a surface chemistry which produces $\mathrm{C}-\mathrm{O}-\mathrm{H}$-containing molecules. In this case, the mobility enhancement of the $\mathrm{CH}_{2} \mathrm{OH}$ radical could be the crucial phenomenon.

Nonetheless, although we have assumed a young chemistry for this source, the enhancement of the $\mathrm{C}-\mathrm{O}-\mathrm{C}$-bearing species towards the compact ridge together with lack of $\mathrm{C}-\mathrm{O}-\mathrm{H}-$ containing molecules in this component could point alternatively to an important role of gas-phase reactions in this component.

Laboratory experiments on ices and surface chemical models may suggest that both $\mathrm{C}-\mathrm{O}-\mathrm{C}$ - and $\mathrm{C}-\mathrm{O}-\mathrm{H}$-containing molecules are released from grains to the gas phase during the warm-up timescales:

- In laboratory experiments to quantify the production rates of COMs, Öberg et al. (2009) identified $\mathrm{CO}$, $\mathrm{CO}_{2}, \mathrm{CH}_{4}, \mathrm{HCO}, \mathrm{H}_{2} \mathrm{CO}, \mathrm{CH}_{2} \mathrm{OH}, \mathrm{CH}_{3} \mathrm{CHO}, \mathrm{CH}_{3} \mathrm{OCH}_{3}$, $\mathrm{CH}_{3} \mathrm{CH}_{2} \mathrm{OH}, \mathrm{OHCH}_{2} \mathrm{CH}_{2} \mathrm{OH}$, and a mixture of complex $\mathrm{CHO}-$ and $\mathrm{COOH}$-containing molecules $(\mathrm{HCOOH}$, $\mathrm{HCOOCH}_{3}, \mathrm{OHCH}_{2} \mathrm{CHO}$ ) after UV photolysis of $\mathrm{CH}_{3} \mathrm{OH}-$ rich ices. Nonetheless, they found a comparatively small formation of $\mathrm{CH}_{3} \mathrm{O}$-containing molecules during warm-up of the irradiated ice.

Owing to the large $\mathrm{CH}_{3} \mathrm{OH}$ abundance found in the present work for all the studied components, we expect $\mathrm{CH}_{3} \mathrm{OH}$-rich ices in our source. However, we note that other processes different from UV radiation which deposit energy to the dust grain (i.e. cosmic ray-grain interactions, grain-grain collisions, IR heating) could lead to different products.

- Chemical models provided by Garrod et al. (2008) show that a wide array of complex species may be formed by reactions involving radicals on dust grains. The reaction of the mobile primary radicals $\mathrm{HCO}$ and $\mathrm{CH}_{3}$ with more strongly bound primary radicals $\mathrm{CH}_{3} \mathrm{O}$ and $\mathrm{CH}_{2} \mathrm{OH}$ results in the formation of $\mathrm{HCOOCH}_{3}, \mathrm{CH}_{3} \mathrm{OCH}_{3}, \mathrm{OHCH}_{2} \mathrm{CHO}$, and $\mathrm{CH}_{3} \mathrm{CH}_{2} \mathrm{OH}$ (i.e. both $\mathrm{C}-\mathrm{O}-\mathrm{C}$ - and $\mathrm{C}-\mathrm{O}-\mathrm{H}$-containing molecules) at temperatures between 30 and $40 \mathrm{~K}$. For the most complex $\mathrm{C}-\mathrm{O}-\mathrm{C}$-bearing molecules, Belloche et al. (2009) proposed that $\mathrm{HCOOCH}_{2} \mathrm{CH}_{3}$ is primarily formed on grains by adding $\mathrm{HCO}$ or $\mathrm{CH}_{3}$ to functional-group radicals derived from $\mathrm{HCOOCH}_{3}$ and $\mathrm{CH}_{3} \mathrm{CH}_{2} \mathrm{OH}$.

With regard to gas chemistry, several gas-phase mechanisms have been proposed to explain the high abundances of several $\mathrm{C}-\mathrm{O}-\mathrm{C}$-bearing molecules:

- To produce $\mathrm{HCOOCH}_{3}$, Neill et al. (2012) proposed ionmolecule reactions in the gas phase that involve the reaction of $\mathrm{CH}_{3} \mathrm{OH}$ and $\mathrm{HCOOH}$.

- Furthermore, Balucani et al. (2015) proposed the nonthermal desorption of iced methanol in cold environments as the precursor of a series of gas-phase reactions, some of them being uncertain radiative association reactions, leading to the formation of $\mathrm{CH}_{3} \mathrm{O}, \mathrm{CH}_{3} \mathrm{OCH}_{3}$, and $\mathrm{HCOOCH}_{3}$.
- Taquet et al. (2016) explained the abundances of $\mathrm{CH}_{3} \mathrm{OCH}_{3}$, $\mathrm{HCOOCH}_{3}, \mathrm{HCOOCH}_{2} \mathrm{CH}_{3}$, and $\mathrm{CH}_{3} \mathrm{CH}_{2} \mathrm{OCH}_{3}$ found in several star-forming regions by means of ion-neutral gasphase chemistry triggered by the evaporation of interstellar ices at temperatures higher than $100 \mathrm{~K}$. The gas-phase chemical network used by these authors assumes $\mathrm{CH}_{3} \mathrm{OH}$ as the main precursor to form $\mathrm{CH}_{3} \mathrm{OCH}_{3}$ and $\mathrm{HCOOCH}_{3}$, and $\mathrm{CH}_{3} \mathrm{CH}_{2} \mathrm{OH}$ as the starting point to produce the most complex species $\left(\mathrm{HCOOCH}_{2} \mathrm{CH}_{3}\right.$ and $\left.\mathrm{CH}_{3} \mathrm{CH}_{2} \mathrm{OCH}_{3}\right)$.

Thus, we could expect that reactions in the gas phase have led to decrease the abundances of $\mathrm{C}-\mathrm{O}-\mathrm{H}$-containing molecules (which emerge in the gas phase more likely by desorption from the ices) and enhance the abundance of $\mathrm{C}-\mathrm{O}-\mathrm{C}$-containing species. If we assume that the released species from the grain mantles are similar for both the compact ridge and the south hot core, the decreased abundance of $\mathrm{CH}_{3} \mathrm{CH}_{2} \mathrm{OH}$ in the former could reflect the formation of $\mathrm{HCOOCH}_{2} \mathrm{CH}_{3}$ and $\mathrm{CH}_{3} \mathrm{CH}_{2} \mathrm{OCH}_{3}$ via the mechanisms proposed by Taquet et al. (2016). This could point out to an advanced evolutionary stage for the compact ridge component.

As an example of the constraints brought by the spatial distribution of the species, it seems that of the two paths to form $\mathrm{HCOOCH}_{2} \mathrm{CH}_{3}$ proposed by Belloche et al. (2009), the one implying a role of $\mathrm{HCOOCH}_{3}$ is favoured in Orion KL. Namely the distribution of $\mathrm{HCOOCH}_{2} \mathrm{CH}_{3}$ resembles that of $\mathrm{HCOOCH}_{3}$, and not that of $\mathrm{CH}_{3} \mathrm{CH}_{2} \mathrm{OH}$. Furthermore, $\mathrm{HCOOCH}_{3}$ could also be similarly the precursor of $\mathrm{CH}_{3} \mathrm{COOCH}_{3}$ on the grain surface through the $\mathrm{COOCH}_{3}$ radical.

\subsection{Warm-up timescales and kinetic temperatures}

On a smaller scale, the two different emission peaks found in the hot core south (EG and ET peaks) may reflect different warm-up timescales and/or different kinetic temperatures of the gas.

Garrod et al. (2008) also proposed that the formation of $\mathrm{CH}_{3} \mathrm{OCH}_{2} \mathrm{OH}$ and $\mathrm{OHCH}_{2} \mathrm{CH}_{2} \mathrm{OH}$ is dependent on the mobility of the $\mathrm{CH}_{3} \mathrm{O}$ and $\mathrm{CH}_{2} \mathrm{OH}$ radicals, respectively. $\mathrm{CH}_{2} \mathrm{OH}$ becomes mobile just as water and other species are beginning to desorb. The grain surface $\mathrm{OHCH}_{2} \mathrm{CH}_{2} \mathrm{OH}$ abundance rises dramatically at $110 \mathrm{~K}$. At temperatures between 50 and $100 \mathrm{~K}$, secondary radicals themselves may become mobile; high temperature mobility of the secondary radical $\mathrm{CH}_{3} \mathrm{CO}$ results in reactions with $\mathrm{CH}_{3}$ and $\mathrm{OH}$ to form $\mathrm{CH}_{3} \mathrm{COCH}_{3}$ and $\mathrm{CH}_{3} \mathrm{COOH}$, respectively. The formation of these secondary radical products is most effective with long warm-up timescales. Therefore, in the ET peak $\mathrm{CH}_{3} \mathrm{CH}_{2} \mathrm{OH}$ and $\mathrm{CH}_{3} \mathrm{OCH}_{2} \mathrm{OH}$ are desorbed after reaction of primary radicals; instead, in the $\mathrm{EG}$ peak the low mobility of the $\mathrm{CH}_{2} \mathrm{OH}$ radical could lead to the desorption of $\mathrm{OHCH}_{2} \mathrm{CH}_{2} \mathrm{OH}$ at similar physical conditions of the $\mathrm{CH}_{3} \mathrm{COOH}$ desorption which is produced after reactions involving secondary radicals.

Interestingly, to explain the high abundance found for $\mathrm{CH}_{3} \mathrm{OCH}_{2} \mathrm{OH}$ in NGC 6334I, McGuire et al. (2017) suggest an important role of low-energy electrons (as a product of the interactions of high-energy radiation, such as cosmic rays, with matter) acting on methanol ices, as studied by Sullivan et al. (2016).

\subsection{Desorption mechanisms}

Different desorption mechanisms could favour the enhancement of different species in the gas phase. The core of the EG peak could be more likely affected by desorption mechanisms via non-thermal processes due to its embedded position in the $\mathrm{SiO}$ 
outflow. In this scenario, sputtering and grain collisions could favour the production of species which, in the mechanism proposed by Garrod et al. (2008), are produced when the dust grain reaches high temperatures and certain radicals (i.e. $\mathrm{CH}_{2} \mathrm{OH}$ and secondary radicals) become mobile. Then, $\mathrm{OHCH}_{2} \mathrm{CH}_{2} \mathrm{OH}$ and $\mathrm{CH}_{3} \mathrm{COOH}$ could be enhanced into the gas phase before the species that warm up at lower temperatures (i.e. $\mathrm{HCOOCH}_{3}$, $\mathrm{CH}_{3} \mathrm{OCH}_{3}, \mathrm{OHCH}_{2} \mathrm{CHO}, \mathrm{CH}_{3} \mathrm{CH}_{2} \mathrm{OH}$ ) reach high abundances. This also explains the spatial distribution of $\mathrm{CH}_{3} \mathrm{COCH}_{3}$ as produced by the interaction of a front shock with its surroundings. The lower diffusion barrier of the $\mathrm{CH}_{3}$ radical (compared to the $\mathrm{OH}$ radical) may also explain the differences found in the spatial distribution of $\mathrm{CH}_{3} \mathrm{COOH}$ and $\mathrm{CH}_{3} \mathrm{COCH}_{3}$.

\subsection{Early stage of shock chemistry}

The co-spatial emission of $\mathrm{HCOOH}, \mathrm{CH}_{3} \mathrm{COOH}$, and $\mathrm{OHCH}_{2} \mathrm{CH}_{2} \mathrm{OH}$ may indicate an early stage of shock chemistry. $\mathrm{HCOOH}$ may be easily liberated from grain surfaces (Garrod et al. 2008), but it could be processed into $\mathrm{HCOOCH}_{3}$ in regions where the timescales are sufficiently long for gas-phase reactions to occur (Neill et al. 2012). This also explains the decreased emission of $\mathrm{HCOOH}$ in the MF and ET peaks. In this scenario, the chemistry found in MF and ET peaks could reflect a prevailing role of gas-phase reactions that take place after sputtering (in a post-shock scenario) and/or thermal evaporation (by compression of the gas in a pre-shock scenario) of the grain mantles. In this respect, if the first generation of mantle molecules might include -OH-bearing species, the first group of species (from $\mathrm{B}$ to $\mathrm{G}$ ) will be characterised by radicals where the $\mathrm{OH}$ bond has been cut (not only $\mathrm{CH}_{3} \mathrm{O}$, but $\mathrm{CH}_{3} \mathrm{CO}$ to form $\mathrm{CH}_{3} \mathrm{COOCH}_{3}$, and $\mathrm{CH}_{3} \mathrm{CH}_{2} \mathrm{O}$ to form $\mathrm{HCOOCH}_{2} \mathrm{CH}_{3}$ and $\mathrm{CH}_{3} \mathrm{CH}_{2} \mathrm{OCH}_{3}$ ).

To sum up, we found an evident difference between the molecular content of the compact ridge and the hot core south, which is reflected in the internal chemical structure of the detected species. This observed spatial differentiation between the most complex O-bearing species could provide an important constraint to future investigations regarding the chemistry of the interstellar medium. Chemical models will have to be adapted to these new results. Finally, to explain this chemical segregation issues such as the evolutionary stage of the different Orion KL components, the composition of the dust grains prior to the collapse phase, the molecules accreted onto the grains, desorption mechanisms in the different regions (ther$\mathrm{mal} / \mathrm{chemical} /$ sputtering/UV processes), and/or the surface and gas-phase chemistry should be addressed in a combined way.

Acknowledgements. We would like to thank the anonymous referee for a helpful report that led to improvements in the paper. The authors thank R. Motiyenko, L. Margulès, and J.-C. Guillemin for their work on methoxymethanol, which was absolutely key to its detection in Orion KL. We thank the ERC for support under grant ERC-2013-Syg-610256- NANOCOSMOS. We also thank the Spanish MINECO for funding support under grants AYA2012-32032 and FIS201452172-C2, and the CONSOLIDER-Ingenio programme "ASTROMOL" CSD 2009-00038.

\section{References}

Allen, V., van der Tak, F. F. S., Sánchez-Monge, Á., Cesaroni, R., \& Beltrán, M. T. 2017, A\&A, 603, A133

Bally, J., Ginsburg, A., Arce, H., et al. 2017, ApJ, 837, 60

Balucani, N., Ceccarelli, C., \& Taquet, V. 2015, MNRAS, 449, L16

Bell, T. A., Cernicharo, J., Viti, S., et al. 2014, A\&A, 564, A114

Belloche, A., Garrod, R. T., Müller, H. S. P., et al. 2009, A\&A, 499, 215

Bergner, J. B., Öberg, K. I., Garrod, R. T., \& Graninger, D. M. 2017, ApJ, 841, 120

Blake, G. A., Sutton, E. C., Masson, C. R., \& Phillips, T. G. 1987, ApJ, 315, 621

Brouillet, N., Despois, D., Baudry, A., et al. 2013, A\&A, 550, A46

Brouillet, N., Despois, D., Lu, X.-H., et al. 2015, A\&A, 576, A129

Cernicharo, J. 2012, in EAS Pub. Ser., eds. C. Stehlé, C. Joblin, \&

L. d'Hendecourt, 58, 251

Cernicharo, J., Kisiel, Z., Tercero, B., et al. 2016, A\&A, 587, L4

Crockett, N. R., Bergin, E. A., Neill, J. L., et al. 2014, ApJ, 787, 112

Favre, C., Despois, D., \& Brouillet, N., et al. 2011a, A\&A, 532, A32

Favre, C., Wootten, H. A., Remijan, A. J., et al. 2011b, ApJ, 739, L12

Favre, C., Pagani, L., Goldsmith, P. F., et al. 2017, A\&A, 604, L2

Fayolle, E. C., Öberg, K. I., Garrod, R. T., van Dishoeck, E. F., \& Bisschop, S. E. 2015, A\&A, 576, A45

Feng, S., Beuther, H., Henning, T., et al. 2015, A\&A, 581, A71

Friedel, D. N., \& Widicus Weaver, S. L. 2012, ApJS, 201, 17

Garrod, R. T., Widicus Weaver, S. L., \& Herbst, E. 2008, ApJ, 682, 283

Genzel, R., \& Stutzki, J. 1989, ARA\&A, 27, 41

Goicoechea, J. R., Chavarría, L., Cernicharo, J., et al. 2015, ApJ, 799, 102

Gómez, L., Rodríguez, L. F., Loinard, L., et al. 2005, ApJ, 635, 1166

Grossschedl, J. E., Alves, J., Meingast, S., et al. 2018, A\&A, 619, A106

Herbst, E., \& van Dishoeck, E. F. 2009, ARA\&A, 47, 427

Hirota, T., Kim, M. K., Kurono, Y., \& Honma, M. 2015, ApJ, 801, 82

Högbom, J. A. 1974, A\&A, 15, 417

Jiménez-Serra, I., Vasyunin, A. I., Caselli, P., et al. 2016, ApJ, 830, L6

Kounkel, M., Hartmann, L., Loinard, L., et al. 2017, ApJ, 834, 142

Luhman, K. L., Robberto, M., Tan, J. C., et al. 2017, ApJ, 838, L3

McGuire, B. A., Shingledecker, C. N., Willis, E. R., et al. 2017, ApJ, 851, L46

Menten, K. M., Reid, M. J., Forbrich, J., \& Brunthaler, A. 2007, A\&A, 474, 515

Motiyenko, R. A., Margulès, L., Despois, D., \& Guillemin, J.-C. 2018, Phys.

Chem. Chem. Phys., (Incorporating Faraday Transactions), 20, 5509

Neill, J. L., Muckle, M. T., Zaleski, D. P., et al. 2012, ApJ, 755, 153

Neill, J. L., Wang, S., Bergin, E. A., et al. 2013, ApJ, 770, 142

Öberg, K. I., Garrod, R. T., van Dishoeck, E. F., \& Linnartz, H. 2009, A\&A, 504, 891

Öberg, K. I., Boamah, M. D., Fayolle, E. C., et al. 2013, ApJ, 771, 95

O'Dell, C. R. 2001, PASP, 113, 29

Pagani, L., Favre, C., Goldsmith, P. F., et al. 2017, A\&A, 604, A32

Peng, T.-C., Despois, D., Brouillet, N., Parise, B., \& Baudry, A. 2012, A\&A, 543, A152

Peng, T.-C., Despois, D., Brouillet, N., et al. 2013, A\&A, 554, A78

Rodríguez, L. F., Dzib, S. A., Loinard, L., et al. 2017, ApJ, 834, 140
Schilke, P., Benford, D. J., Hunter, T. R., Lis, D. C., \& Phillips, T. G. 2001, ApJS, 132, 281

Sullivan, K. K., Boamah, M. D., Shulenberger, K. E., et al. 2016, MNRAS, 460, 664

Suzuki, T., Ohishi, M., Saito, M., et al. 2018, ApJS, 237, 3

Taquet, V., Wirström, E. S., \& Charnley, S. B. 2016, ApJ, 821, 46

Tercero, B., Cernicharo, J., Pardo, J. R., \& Goicoechea, J. R. 2010, A\&A, 517, A96

Tercero, B., Vincent, L., Cernicharo, J., Viti, S., \& Marcelino, N. 2011, A\&A, 528, A26

Tercero, B., Cernicharo, J., López, A., et al. 2015, A\&A, 582, L1

Widicus Weaver, S. L., \& Friedel, D. N. 2012, ApJS, 201, 16

Wright, M. C. H., \& Plambeck, R. L. 2017, ApJ, 843, 83

Wu, Y., Liu, T., \& Qin, S.-L. 2014, ApJ, 791, 123

Zapata, L. A., Schmid-Burgk, J., Ho, P. T. P., Rodríguez, L. F., \& Menten, K. M. 2009, ApJ, 704, L45

Zapata, L. A., Loinard, L., Schmid-Burgk, J., et al. 2011, ApJ, 726, L12 
B. Tercero et al.: Chemical segregation of complex organic O-bearing species in Orion KL

\section{Appendix A: Table of rotational transitions}

Table A.1. Selected rotational transitions of each O-bearing COM plotted in Fig. 1.

\begin{tabular}{|c|c|c|c|c|c|c|c|}
\hline Map & Molecule & Transition & $\begin{array}{l}\text { Frequency } \\
(\mathrm{MHz})\end{array}$ & $\begin{array}{r}E_{\text {upp }} \\
(\mathrm{K}) \\
\end{array}$ & $\begin{array}{c}A_{\mathrm{ul}} \\
\left(\mathrm{s}^{-1}\right)\end{array}$ & $\begin{array}{l}\text { Scale } \\
\left(\mathrm{Jy} \mathrm{km} \mathrm{beam}^{-1} \mathrm{~s}^{-1}\right)\end{array}$ & Notes \\
\hline \multirow[t]{3}{*}{ A } & \multirow[t]{3}{*}{${ }^{13} \mathrm{CH}_{3} \mathrm{OH}$} & $8_{4,4} \rightarrow 9_{3,7} ; \mathrm{A}$ & 215722.475 & 162.3 & $9.1 \times 10^{-6}$ & colour: 0.05 to 3.5 & \\
\hline & & $5_{-2,4} \rightarrow 4_{-2,3} ; \mathrm{E}$ & 236062.000 & 52.1 & $3.8 \times 10^{-5}$ & contour: 0.05 to 36 by 3.0 & \\
\hline & & $5_{2,3} \rightarrow 4_{2,2} ; \mathrm{E}$ & 236062.850 & 48.5 & $3.8 \times 10^{-5}$ & & \\
\hline \multirow[t]{2}{*}{ B } & \multirow[t]{2}{*}{$\mathrm{HCOOCH}_{3}$} & $10_{4,6} \rightarrow 9_{3,7} ; \mathrm{A}$ & 221717.125 & 43.2 & $1.0 \times 10^{-5}$ & colour: 0.05 to 6.5 & \\
\hline & & $27_{-9,18} \rightarrow 27_{-8,19} ; \mathrm{E}$ & 222367.071 & 277.3 & $1.5 \times 10^{-5}$ & contour: 0.05 to 3.6 by 0.3 & \\
\hline \multirow[t]{8}{*}{$\mathrm{C}$} & \multirow[t]{8}{*}{$\mathrm{CH}_{3} \mathrm{OCH}_{3}$} & $14_{1,13} \rightarrow 13_{2,12} ; \mathrm{AA}$ & 226346.051 & 98.9 & $3.3 \times 10^{-5}$ & colour: 0.07 to 25 & $a$ \\
\hline & & $14_{1,13} \rightarrow 13_{2,12} ; \mathrm{EE}$ & 226346.927 & 98.9 & $3.3 \times 10^{-5}$ & & \\
\hline & & $14_{1,13} \rightarrow 13_{2,12} ; \mathrm{AE}$ & 226347.803 & 98.9 & $3.3 \times 10^{-5}$ & & \\
\hline & & $14_{1,13} \rightarrow 13_{2,12} ; \mathrm{EA}$ & 226347.804 & 98.9 & $3.3 \times 10^{-5}$ & & \\
\hline & & $24_{4,21} \rightarrow 24_{3,22} ; \mathrm{EA}$ & 225202.460 & 296.4 & $4.7 \times 10^{-5}$ & contour: 0.07 to 15 by 1.0 & \\
\hline & & $24_{4,21} \rightarrow 24_{3,22} ; \mathrm{AE}$ & 225202.460 & 296.4 & $4.7 \times 10^{-5}$ & & \\
\hline & & $24_{4,21} \rightarrow 24_{3,22} ; \mathrm{EE}$ & 225203.946 & 296.4 & $4.7 \times 10^{-5}$ & & \\
\hline & & $24_{4,21} \rightarrow 24_{3,22} ; \mathrm{AA}$ & 225205.431 & 296.4 & $4.7 \times 10^{-5}$ & & \\
\hline \multirow[t]{3}{*}{$\mathrm{D}$} & \multirow[t]{3}{*}{$\mathrm{CH}_{2} \mathrm{OCH}_{2}$} & $7_{2,6} \rightarrow 6_{1,5} ;$ ortho & 226072.102 & 47.0 & $1.7 \times 10^{-4}$ & colour: 0.10 to 5.5 & $b$ \\
\hline & & $18_{6,12} \rightarrow 18_{5,13} ;$ ortho & 234979.289 & 321.6 & $9.2 \times 10^{-5}$ & contour: 0.05 to 1.7 by 0.15 & \\
\hline & & $18_{7,12} \rightarrow 18_{6,13} ;$ para & 234979.462 & 319.9 & $9.2 \times 10^{-5}$ & & \\
\hline \multirow[t]{2}{*}{$\mathrm{E}$} & \multirow[t]{2}{*}{$\mathrm{CH}_{3} \mathrm{COOCH}_{3}$} & $18_{-9,9} \rightarrow 1_{-8,9} ; \mathrm{EA}$ & 242955.602 & 86.3 & $1.0 \times 10^{-4}$ & colour: 0.05 to 0.65 & $c$ \\
\hline & & $14_{9,6} \rightarrow 13_{8,6} ; \mathrm{AE}$ & 216462.024 & 63.0 & $9.2 \times 10^{-5}$ & contour: 0.05 to 0.35 by 0.05 & \\
\hline \multirow[t]{2}{*}{$\mathrm{F}$} & \multirow[t]{2}{*}{$\mathrm{HCOOCH}_{2} \mathrm{CH}_{3}$} & $43_{6,38} \rightarrow 42_{6,37} ;$ trans & 237566.732 & 275.9 & $2.6 \times 10^{-4}$ & colour: 0.05 to 0.40 & $d$ \\
\hline & & $43_{1,42} \rightarrow 42_{1,41} ;$ trans & 228399.191 & 247.0 & $2.3 \times 10^{-4}$ & contour: 0.05 to 0.40 by 0.05 & $e$ \\
\hline \multirow[t]{10}{*}{ G } & \multirow[t]{10}{*}{$\mathrm{CH}_{3} \mathrm{CH}_{2} \mathrm{OCH}_{3}$} & $31_{1,31} \rightarrow 30_{0,30} ; \mathrm{EE}^{\prime}$ & 245274.088 & 188.8 & $9.5 \times 10^{-5}$ & colour: 0.02 to 0.90 & $f$ \\
\hline & & $31_{1,31} \rightarrow 30_{0,30} ; \mathrm{EE}$ & 245274.088 & 188.8 & $9.5 \times 10^{-5}$ & & \\
\hline & & $31_{1,31} \rightarrow 30_{0,30} ; \mathrm{AE}$ & 245274.098 & 188.8 & $4.8 \times 10^{-5}$ & & \\
\hline & & $31_{1,31} \rightarrow 30_{0,30}$; EA & 245274.211 & 188.8 & $4.8 \times 10^{-5}$ & & \\
\hline & & $31_{1,31} \rightarrow 30_{0,30} ; \mathrm{AA}$ & 245274.221 & 188.8 & $4.8 \times 10^{-5}$ & & \\
\hline & & $23_{2,22} \rightarrow 22_{1,21} ; \mathrm{EE}^{\prime}$ & 225494.508 & 111.0 & $3.4 \times 10^{-5}$ & contour: 0.05 to 0.35 by 0.05 & $g$ \\
\hline & & $23_{2,22} \rightarrow 22_{1,21} ; \mathrm{EE}$ & 225494.508 & 111.0 & $3.4 \times 10^{-5}$ & & \\
\hline & & $23_{2,22} \rightarrow 22_{1,21} ; \mathrm{AE}$ & 225494.625 & 111.0 & $1.7 \times 10^{-5}$ & & \\
\hline & & $23_{2,22} \rightarrow 22_{1,21} ; \mathrm{EA}$ & 225495.848 & 111.0 & $1.7 \times 10^{-5}$ & & \\
\hline & & $23_{2,22} \rightarrow 22_{1,21} ;$ AA & 225495.965 & 111.0 & $1.7 \times 10^{-5}$ & & \\
\hline \multirow[t]{5}{*}{$\mathrm{H}$} & \multirow[t]{5}{*}{$\mathrm{HCOOH}$} & $10_{7,4} \rightarrow 9_{7,3}$ & 224911.799 & 215.0 & $6.5 \times 10^{-5}$ & colour: 0.05 to 1.7 & \\
\hline & & $10_{7,3} \rightarrow 9_{7,2}$ & 224911.799 & 215.0 & $6.5 \times 10^{-5}$ & & \\
\hline & & $10_{8,2} \rightarrow 9_{8,1}$ & 224911.894 & 262.6 & $4.6 \times 10^{-5}$ & & \\
\hline & & $10_{8,3} \rightarrow 9_{8,2}$ & 224911.894 & 262.6 & $4.6 \times 10^{-5}$ & & \\
\hline & & $10_{0,10} \rightarrow 9_{0,9}$ & 220037.942 & 58.6 & $1.2 \times 10^{-4}$ & contour: 0.05 to 3.2 by 0.20 & \\
\hline \multirow[t]{3}{*}{$\mathrm{I}$} & \multirow[t]{3}{*}{$\mathrm{OHCH}_{2} \mathrm{CH}_{2} \mathrm{OH}$} & $23_{9,15} \rightarrow 22_{9,14} ; \mathrm{ag}$ & 242947.990 & 176.1 & $3.0 \times 10^{-4}$ & colour: 0.05 to 2.3 & $h$ \\
\hline & & $23_{9,14} \rightarrow 22_{9,13} ;$ ag & 242948.591 & 176.1 & $3.0 \times 10^{-4}$ & & \\
\hline & & $23_{2,22} \rightarrow 22_{2,21} ; \mathrm{ag}$ & 228752.776 & 132.8 & $2.9 \times 10^{-4}$ & contour: 0.05 to 2.0 by 0.20 & $i$ \\
\hline \multirow[t]{4}{*}{$\mathrm{J}$} & \multirow[t]{4}{*}{$\mathrm{CH}_{3} \mathrm{COOH}$} & $20_{0,20} \rightarrow 19_{0,19} ; \mathrm{E}$ & 218010.014 & 112.1 & $1.7 \times 10^{-4}$ & colour: 0.05 to 1.8 & $j$ \\
\hline & & $20_{0,20} \rightarrow 19_{1,19} ; \mathrm{E}$ & 218010.014 & 112.1 & $2.3 \times 10^{-8}$ & & \\
\hline & & $20_{1,20} \rightarrow 19_{0,19} ; \mathrm{E}$ & 218010.014 & 118.8 & $2.3 \times 10^{-8}$ & & \\
\hline & & $20_{1,20} \rightarrow 19_{1,19} ; \mathrm{E}$ & 218010.014 & 118.8 & $1.7 \times 10^{-4}$ & & \\
\hline
\end{tabular}

Notes. ${ }^{(a)}$ Partially blended with $\mathrm{CH}_{3} \mathrm{OD}\left(\mathrm{E}, 5_{0} \rightarrow 4_{0}\right)$ in the blue wing. However, to map the $\mathrm{CH}_{3} \mathrm{OCH}_{3}$ emission, we avoided the contribution of $\mathrm{CH}_{3} \mathrm{OD}$ by selecting an appropriate interval of velocities (see Fig. C.1). ${ }^{(b)}$ Cernicharo et al. (2016). ${ }^{(c)}$ Partially blended with the red wing of a $\mathrm{CH}_{2}$ DCN line $\left(14_{6,8} \rightarrow 13_{6,7} \& 14_{6,9} \rightarrow 13_{6,8}\right)$ in the EG and ET peaks. ${ }^{(d)}$ Tercero et al. $(2015) .{ }^{\left({ }^{e}\right)}$ Blended with the red wing of a U line at $228408 \mathrm{MHz}$ (assuming a $v_{\mathrm{LSR}}$ of $7.5 \mathrm{~km} \mathrm{~s}^{-1}$ ) in the EG and ET peaks. ${ }^{(f)}$ Tercero et al. (2015); partially blended with some emission from extreme velocities of ${ }^{34} \mathrm{SO}_{2}\left(6_{3,3} \rightarrow 6_{2,4}\right)$ and $\mathrm{SO}_{2}\left(26_{3,23} \rightarrow 25_{4,22}\right)$ in the EG and ET peaks. Nevertheless, the emission at MF peak is not blended (see Fig. C.1). ${ }^{(g)}$ Blended with some emission from extreme velocities of $\mathrm{SO}^{18} \mathrm{O}\left(12_{1,12} \rightarrow 11_{0,11}\right), \mathrm{CH}_{2} \mathrm{DCN}\left(13_{8,5} \rightarrow 12_{8,4} \& 13_{8,6} \rightarrow 12_{8,5}\right)$, and $\mathrm{HCOOH}\left(10_{3,7} \rightarrow 9_{3,6}\right)$ in the EG and ET peaks. Nevertheless, the emission at MF peak is not blended (see Fig. C.1). ${ }^{(h)}$ Cernicharo et al. (2016). ${ }^{(i)}$ Brouillet et al. (2015). ${ }^{(j)}$ Cernicharo et al. (2016). ${ }^{(k)}$ Cernicharo et al. (2016). ${ }^{(l)}$ Cernicharo et al. (2016); partially blended with the red wing of a $\mathrm{CH}_{2} \mathrm{DCN}$ line $\left(14_{6,8} \rightarrow 13_{6,7} \& 14_{6,9} \rightarrow 13_{6,8}\right)$ in the EG and ET peaks. ${ }^{(m)}$ Blended with some emission from extreme velocities of $\mathrm{NH}_{2} \mathrm{CHO}$ $\left(11_{2,10} \rightarrow 10_{2,9}\right)$ in the EG and ET peaks. ${ }^{(n)}$ Cernicharo et al. (2016). 
Table A.1. continued.

\begin{tabular}{|c|c|c|c|c|c|c|c|}
\hline Map & Molecule & Transition & $\begin{array}{l}\text { Frequency } \\
(\mathrm{MHz})\end{array}$ & $\begin{array}{r}E_{\text {upp }} \\
(\mathrm{K})\end{array}$ & $\begin{array}{c}A_{\mathrm{ul}} \\
\left(\mathrm{s}^{-1}\right)\end{array}$ & $\begin{array}{l}\text { Scale } \\
\left(\mathrm{Jy} \mathrm{km} \mathrm{beam}^{-1} \mathrm{~s}^{-1}\right)\end{array}$ & Notes \\
\hline & & $22_{0,22} \rightarrow 21_{1,21} ; \mathrm{E}$ & 239305.851 & 134.6 & $4.4 \times 10^{-5}$ & contour: 0.05 to 2.5 by 0.20 & \\
\hline & & $22_{1,22} \rightarrow 21_{0,21} ; \mathrm{E}$ & 239305.851 & 134.6 & $4.4 \times 10^{-5}$ & & \\
\hline & & $22_{0,22} \rightarrow 21_{0,21} ; \mathrm{E}$ & 239305.851 & 134.6 & $1.8 \times 10^{-4}$ & & \\
\hline & & $22_{1,22} \rightarrow 21_{1,21} ; \mathrm{E}$ & 239305.851 & 134.6 & $1.8 \times 10^{-4}$ & & \\
\hline \multirow[t]{2}{*}{$\mathrm{K}$} & \multirow[t]{2}{*}{$\mathrm{CH}_{3} \mathrm{CH}_{2} \mathrm{OH}$} & $20_{5,15} \rightarrow 20_{4,16} ;$ trans & 222217.285 & 208.3 & $6.5 \times 10^{-5}$ & colour: 0.05 to 6.5 & $k$ \\
\hline & & $8_{5,3} \rightarrow 8_{4,4} ;$ trans & 234984.238 & 61.6 & $5.8 \times 10^{-5}$ & contour: 0.05 to 8.0 by 1.0 & \\
\hline \multirow[t]{6}{*}{$\mathrm{L}$} & \multirow[t]{6}{*}{$\mathrm{CH}_{3} \mathrm{OCH}_{2} \mathrm{OH}$} & $22_{10,12} \rightarrow 21_{10,11}$ & 229025.777 & 184.0 & $3.9 \times 10^{-6}$ & colour: 0.05 to 2.0 & \\
\hline & & $22_{10,13} \rightarrow 21_{10,12}$ & 229027.637 & 184.0 & $3.9 \times 10^{-6}$ & & \\
\hline & & $22_{10,12} \rightarrow 21_{10,11}$ & 229027.637 & 184.0 & $3.9 \times 10^{-6}$ & & \\
\hline & & $22_{10,13} \rightarrow 21_{10,12}$ & 229028.550 & 184.0 & $3.9 \times 10^{-6}$ & & \\
\hline & & $23_{4,19} \rightarrow 22_{4,18}$ & 246243.055 & 148.9 & $5.9 \times 10^{-6}$ & contour: 0.05 to 1.8 by 0.20 & \\
\hline & & $23_{4,19} \rightarrow 22_{4,18}$ & 246246.232 & 148.9 & $5.9 \times 10^{-6}$ & & \\
\hline \multirow[t]{5}{*}{ M } & \multirow[t]{5}{*}{$\mathrm{OHCH}_{2} \mathrm{CHO}$} & $24_{0,24} \rightarrow 23_{1,23}$ & 242957.815 & 148.3 & $4.2 \times 10^{-4}$ & colour: 0.05 to 0.70 & l \\
\hline & & $24_{1,24} \rightarrow 23_{1,23}$ & 242957.904 & 148.3 & $5.6 \times 10^{-6}$ & & \\
\hline & & $24_{0,24} \rightarrow 23_{0,23}$ & 242957.983 & 148.3 & $5.6 \times 10^{-6}$ & & \\
\hline & & $24_{1,24} \rightarrow 23_{0,23}$ & 242958.072 & 148.3 & $4.2 \times 10^{-4}$ & & \\
\hline & & $22_{1,21} \rightarrow 21_{2,20}$ & 232286.154 & 134.5 & $3.1 \times 10^{-4}$ & contour: 0.05 to 0.45 by 0.05 & $m$ \\
\hline \multirow[t]{8}{*}{$\mathrm{N}$} & \multirow[t]{8}{*}{$\mathrm{CH}_{3} \mathrm{COCH}_{3}$} & $22_{1,21} \rightarrow 21_{2,20} ; \mathrm{EE}$ & 229055.797 & 132.8 & $8.2 \times 10^{-5}$ & colour: 0.07 to 18 & $n$ \\
\hline & & $22_{1,21} \rightarrow 21_{1,20} ; \mathrm{EE}$ & 229055.797 & 132.8 & $4.6 \times 10^{-4}$ & & \\
\hline & & $22_{2,21} \rightarrow 21_{2,20} ; \mathrm{EE}$ & 229055.797 & 132.8 & $4.4 \times 10^{-4}$ & & \\
\hline & & $22_{2,21} \rightarrow 21_{1,20} ; \mathrm{EE}$ & 229055.797 & 132.8 & $9.7 \times 10^{-5}$ & & \\
\hline & & $20_{2,18} \rightarrow 19_{3,17} ; \mathrm{AE}$ & 218091.411 & 119.0 & $4.3 \times 10^{-4}$ & contour: 0.07 to 9.0 by 1.0 & \\
\hline & & $20_{3,18} \rightarrow 19_{2,17} ; \mathrm{AE}$ & 218091.411 & 119.0 & $4.3 \times 10^{-4}$ & & \\
\hline & & $20_{2,18} \rightarrow 19_{3,17} ; \mathrm{EA}$ & 218091.448 & 119.0 & $4.3 \times 10^{-4}$ & & \\
\hline & & $20_{3,18} \rightarrow 19_{2,17} ; \mathrm{EA}$ & 218091.448 & 119.0 & $4.3 \times 10^{-4}$ & & \\
\hline
\end{tabular}

\section{Appendix B: Determination of column densities}

To model the emission of the studied species towards the MF, EG, and ET peaks, we extracted an averaged spectrum over $5 \times 5$ pixels $\left(1^{\prime \prime} \times 1^{\prime \prime}\right)$ around the emission peaks mentioned above, and using MADEX we calculated the synthetic spectrum between 213.7 GHz and $246.7 \mathrm{GHz}$ for the different species and positions according to the physical parameters collected in Table B.1. Owing to the lack of collisional rates for most of the studied species, we used the local thermodynamic equilibrium (LTE) approximation. Taking into account the physical conditions of the considered components of the cloud (see Table B.1), we expect this approximation to work reasonably well.

For each spectral component and species, we assumed uniform physical conditions of the cloud: line width, radial velocity, and a source size slightly larger than the spatial resolution of these observations ( $\left.3^{\prime \prime}\right)$. Therefore, we left only the rotational temperature and the molecular column density as free parameters. However, as a first step, we relied on previous works (see e.g. Tercero et al. 2015; Cernicharo et al. 2016) to fix the rotational temperature at $150 \mathrm{~K}$. Then we varied the column density to obtain an agreement in line intensity between model and observations better than $\sim 30 \%$ for all features of the studied species present in the frequency range of the ALMA SV data. Lines for which this condition was not fulfilled were revised searching for possible blendings with features from other molecular species. Finally, we adopted the model parameters if all spectral features that did not match with the synthetic spectrum were blended. We marked as the upper limit the column density results obtained with less than five unblended lines.

For certain species, some mismatches between model and data could not be explained due to line blending. We noted that lines which showed these discrepancies were high- and/or lowexcitation lines. In these cases, we introduced a hotter (at $250 \mathrm{~K}$ ) and/or colder (at $50 \mathrm{~K}$ ) component to properly fit all unblended lines by varying the column densities of the different temperature components and following the criteria discussed above. The derived column density shown in Table B.1 is the sum of the values obtained for the different temperature components.

In addition, for the most abundant species other components at different radial velocities have been included to reproduce the observed line profiles (see Table B.1). We consider that these extra components come from adjacent parts of the region that partially overlap with the emission from the considered emission peaks. 
B. Tercero et al.: Chemical segregation of complex organic O-bearing species in Orion KL

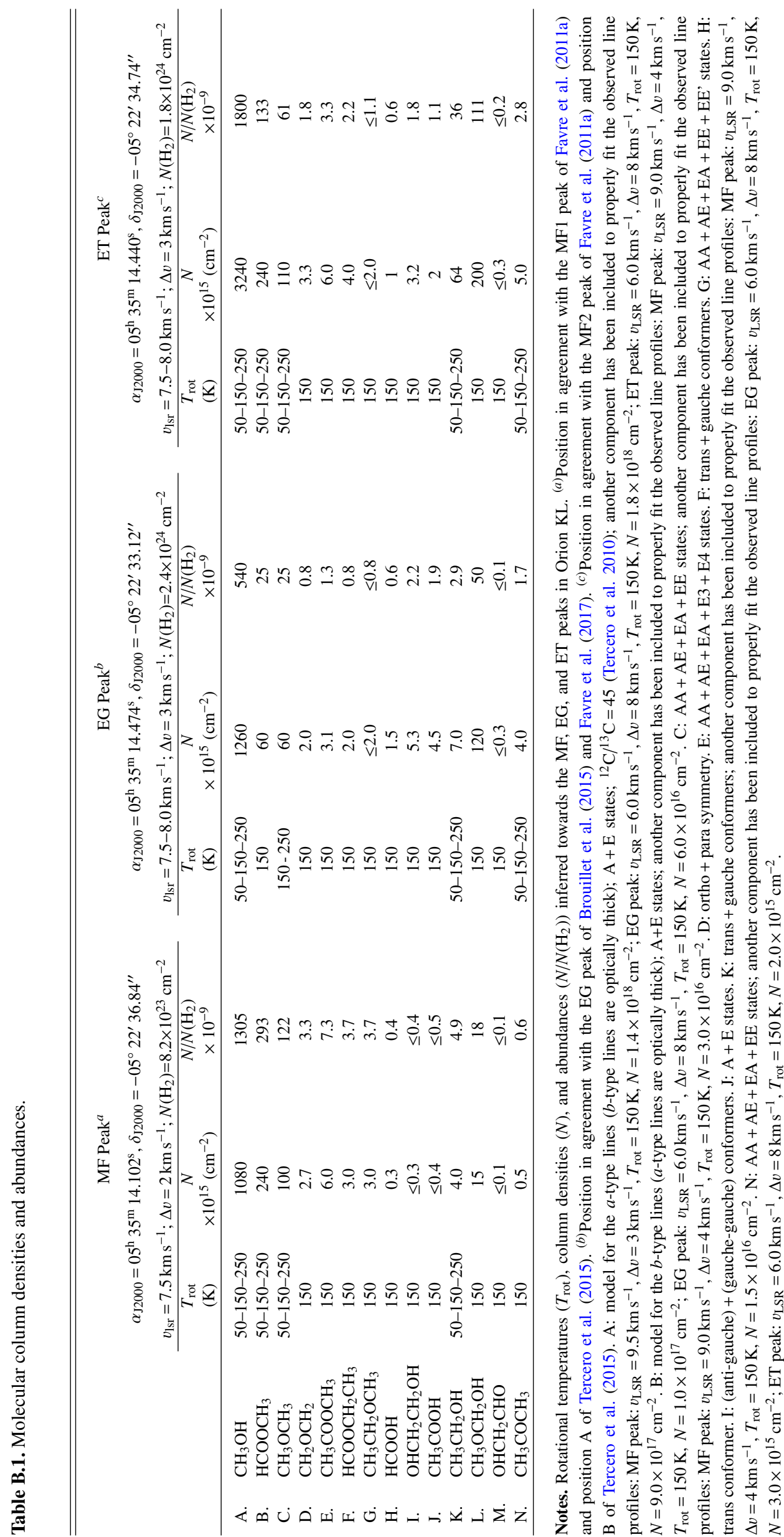




\section{Appendix C: Complementary figures}

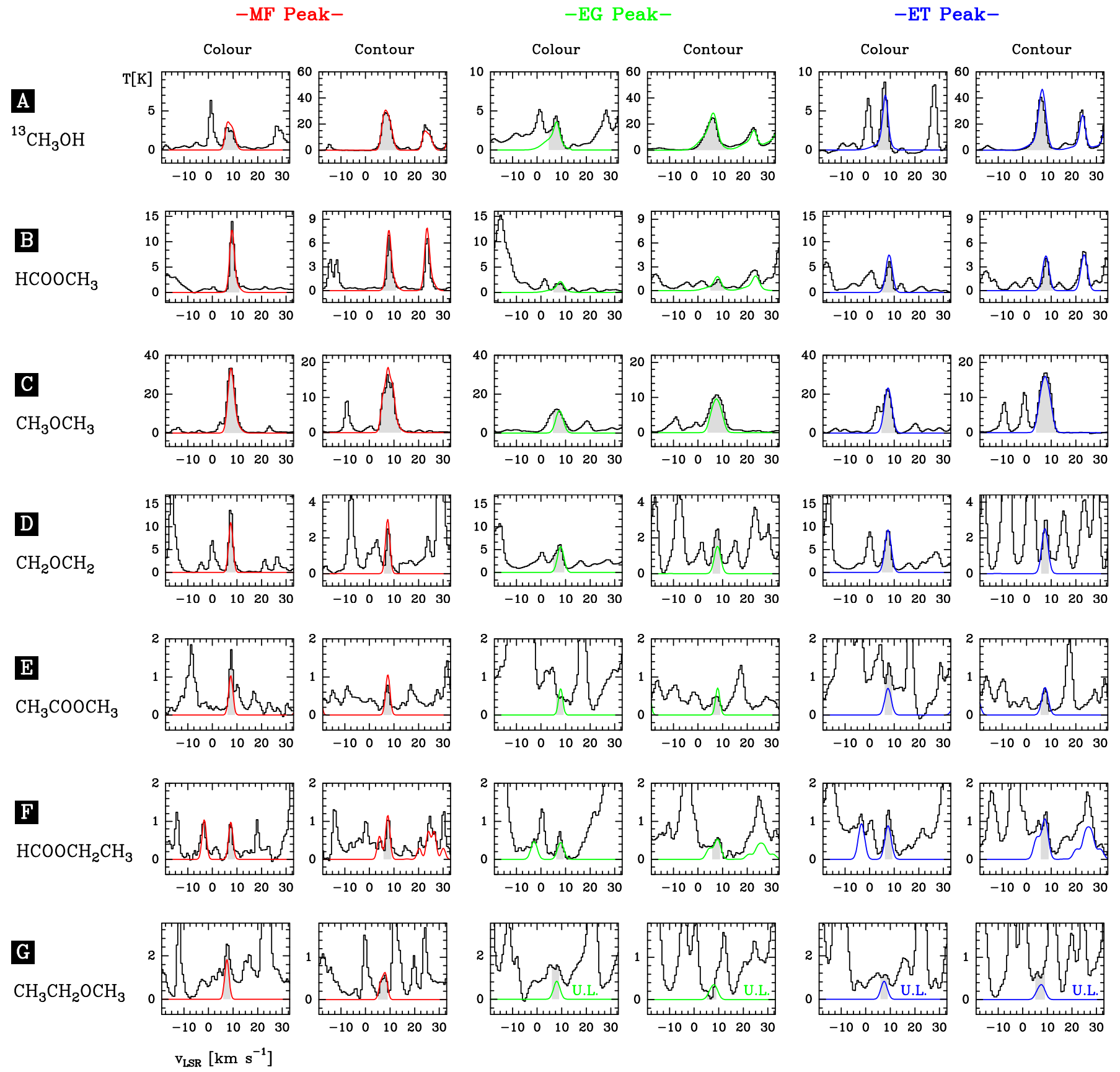

Fig. C.1. Lines mapped in Fig. 1 (colour and contour) in the three selected positions (MF, EG, and ET peaks). The data (black histogram spectra) are from ALMA Science Verification observations. The quantum numbers of the selected lines and their spectroscopic parameters are listed in Table A.1. We also show the adopted integrated area for imaging the spatial distribution of each line (Fig. 1).The red, green, and blue curves show our best LTE models for the emission of each molecule in each position (see Table B.1). The label U.L. indicates that the column density of the model is only an upper limit. The intensity scale has been maintained for the same line (colour or contour) in the three Orion components. 
B. Tercero et al.: Chemical segregation of complex organic O-bearing species in Orion KL

-MF Peak-
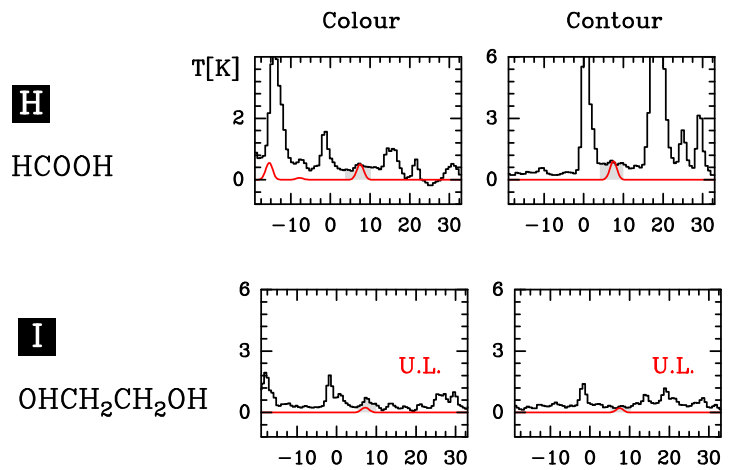

J

$\mathrm{CH}_{3} \mathrm{COOH}$
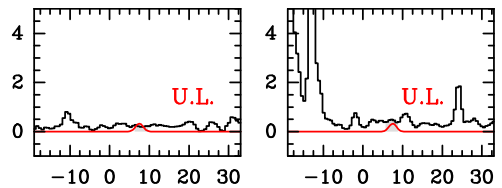

K

$\mathrm{CH}_{3} \mathrm{CH}_{2} \mathrm{OH}$
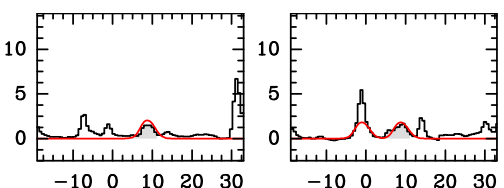

L

$\mathrm{CH}_{3} \mathrm{OCH}_{2} \mathrm{OH}$
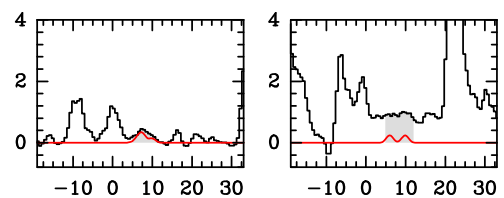

M

$\mathrm{OHCH}_{2} \mathrm{CHO}$
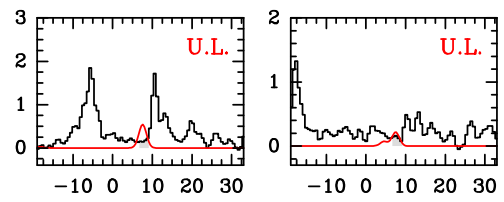

N

$\mathrm{CH}_{3} \mathrm{COCH}_{3}$
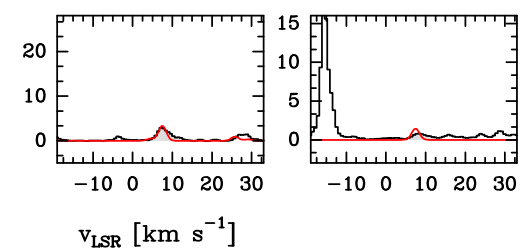

$\begin{array}{lllll}-10 & 0 & 10 & 20 & 30\end{array}$ $\mathrm{v}_{\mathrm{LSR}}\left[\mathrm{km} \mathrm{s}^{-1}\right]$
-EG Peak-
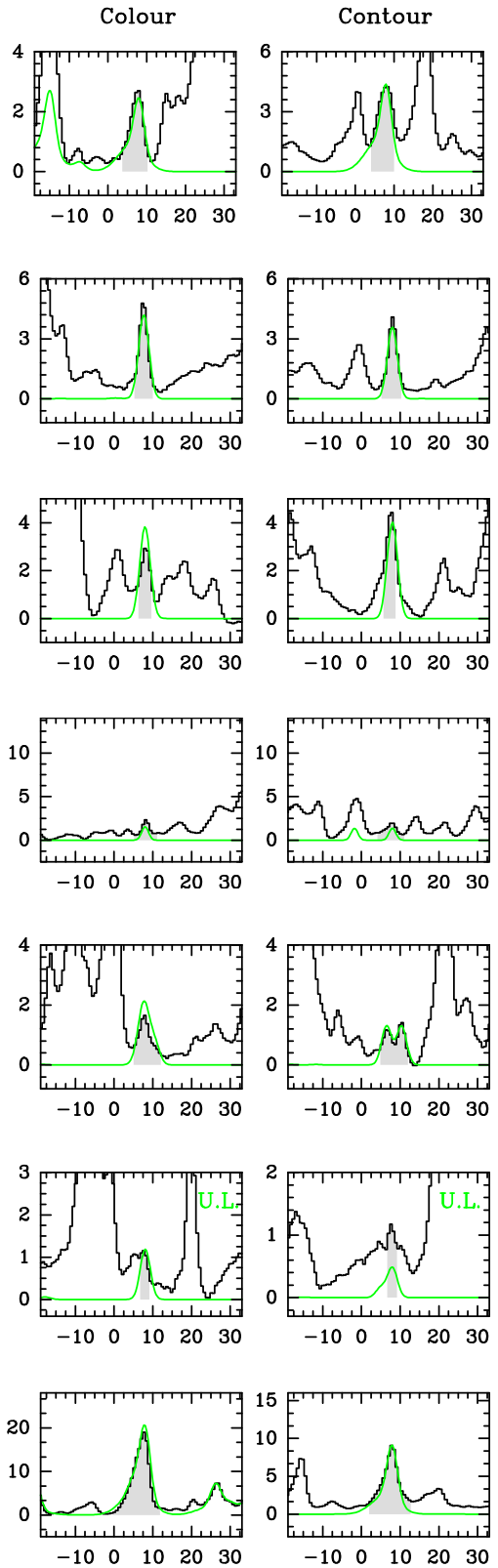

$\begin{array}{llllllllll}-10 & 0 & 10 & 20 & 30 & -10 & 0 & 10 & 20 & 30\end{array}$
-ET Peak-
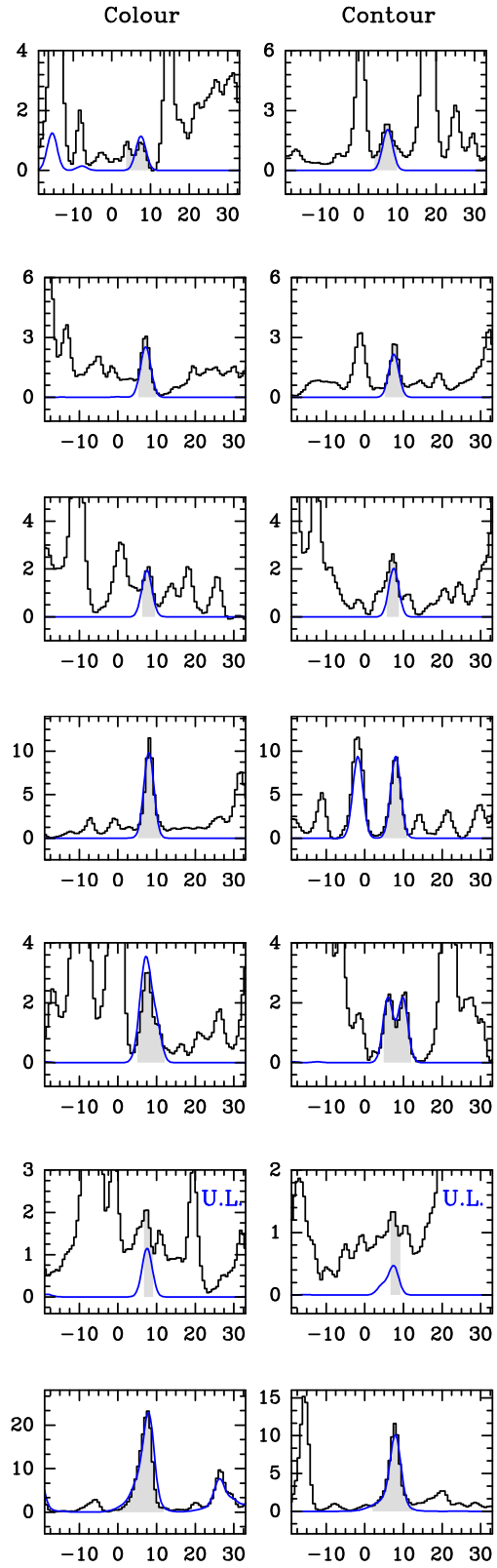

Fig. C.1. continued. 

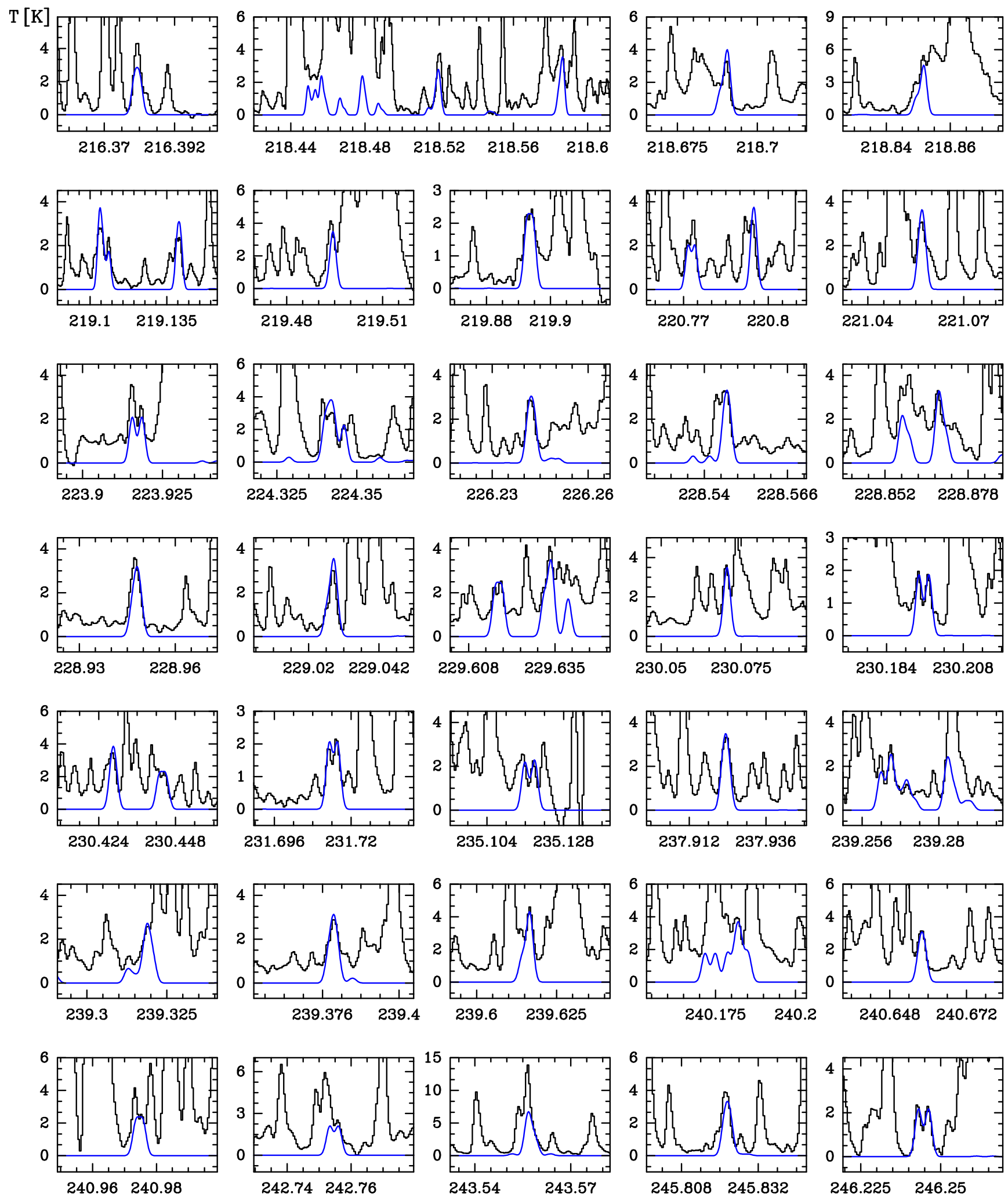

Frequency [GHz]

Fig. C.2. Selected lines of $\mathrm{CH}_{3} \mathrm{OCH}_{2} \mathrm{OH}$ towards the ET peak detected with the ALMA interferometer. A $v_{\mathrm{LSR}}$ of $+7.5 \mathrm{~km} \mathrm{~s}{ }^{-1}$ is assumed. 